\title{
GESTAÇÃO NA ADOLESCÊNCIA: ANÁLISE DO PERFIL DE GESTANTES ADOLESCENTES E DESFECHO PERINATAL REALIZADO NO HOSPITAL JÚLIA KUBITSCHEK
}

\author{
Caroline Cássia de Morais \\ Hospital Júlia Kubitschek/FHEMIG \\ carolinecmorais@hotmail.com \\ Jane Savoi Silveira \\ janesavoi@gmail.com \\ Ana Christina de Lacerda Lobato \\ anacllobato@gmail.com \\ Luciana Vieira Martins \\ Hospital Júlia Kubitschek/FHEMIG \\ luvmartins@yahoo.com.br
}

\section{RESUMO}

INTRODUÇÃO: A gravidez na adolescência impacta na estrutura socioeconômica, biológica, familiar e emocional. OBJETIVO: Analisar o perfil epidemiológico de gestantes adolescentes atendidas no pré-natal no Hospital Júlia Kubitschek. METODOLOGIA: Estudo observacional, transversal envolvendo 186 pacientes atendidas entre os anos de 2018 a 2020 através de entrevista com questionário estruturado aplicado na primeira consulta de pré-natal em uma maternidade de referência de Belo Horizonte. RESULTADOS: O estudo acompanhou gestantes entre II a I7 anos de idade sendo a primiparidade relatada em 9I,9\% dos casos. Cerca de $75,3 \%$ das participantes eram solteiras e a maioria residia com a família/pais. O principal provedor foi a mãe das adolescentes com renda em média de um salário mínimo. Cerca de 38,2\% abandonaram os estudos e 13,8\% foi devido a gestação. A média de início da atividade sexual foi de I4 anos e menos de I6\% relataram gestação planejada. Todas as entrevistadas conheciam pelo menos algum método contraceptivo e cerca de $78 \%$ relataram uso inconsistente dos métodos contraceptivos principalmente porque não quiseram usar o método (30,6\%). 61,5\% das entrevistas relataram que a mãe delas teve filhos na adolescência com média de idade de 15,9 anos. Cerca de $82,9 \%$ das participantes evoluíram para via de parto vaginal, $17,1 \%$ via de parto cesariana, sendo $15 \%$ dos partos prematuros. A média de peso dos recém-nascidos foi de 2.900 gramas enquanto a média do Apgar do primeiro minuto foi de 8,I e do segundo minuto de 9. CONCLUSÃO: Entender o perfil das adolescentes permite intervenções e melhorias nos processos de educação sexual, promoção do uso consistente e correto de contraceptivos através do acolhimento, da confidencialidade, visando a assistência multidisciplinar.

PALAVRAS-CHAVE: gravidez na adolescência, adolescente, comportamento sexual 